\title{
УРОВЕНЬ ТЕНЕВОЙ ЭКОНОМИКИ В СТРАНАХ ЕАЭС В УСЛОВИЯХ НАЛОГОВОЙ ГАРМОНИЗАЦИИ*
}

\begin{abstract}
Д.Ю. Федотов *
Проведен сравнительный анализ уровня теневой экономики в странах Евразийского экономического союза, дана оценка влияния налогов на изменение ее масштабов. Рассмотрены предпринимаемые шаги по налоговой гармонизации, заключающейся в унификации и систематизации налогов на территории стран ЕАЭС, координации их налоговой политики и налоговых систем. С помощью статистических методов сделан корреляционный анализ зависимости размера теневой экономики от величины налоговой нагрузки (доли налогов в ВВП). Для выявления специфики развития налоговых процессов и «тенезации» бизнеса проведено сравнение отраслевой структуры налогоплательщиков в Беларуси и России. Полученные результаты позволили подтвердить первоначально выдвинутую гипотезу о том, что высокая налоговая нагрузка не является ведущим фактором, провоцирующим хозяйствующих субъектов уходить в «тень» с целью уклонения от уплаты налогов,
\end{abstract}

Ключевые слова: налог, налоговая нагрузка, теневая экономика, отраслевая экономика, Евразийский экономический союз.

JEL-классификация: H26, О17.

DOI: $10.46782 / 1818-4510-2021-2-55-62$

Материал поступил 13.04.2021 2.

Теневая экономика, как социальное явление, заключающееся в осуществлении хозяйственной деятельности вне государственного контроля и учета, наблюдается во всех странах мира независимо от уровня их экономического развития. Наиболее остро эта проблема проявляется в развивающихся странах, в том числе входящих в Евразийский экономический союз. На протяжении 20102015 гг. величина теневой экономики в большинстве стран ЕАЭС несколько снижалась, достигнув 31-36\% от величины ВВП (рис. 1), что в несколько раз превосходит уровень развитых стран мира, таких как Швейцария, Германия, Япония.

Исследователи, изучающие теневую экономику, расходятся во мнении о при-

* Исследование выполнено при финансовой поддержке РФФИ в рамках научно-исследовательского проекта № 19-010-00365А «Теневая экономика и ее отраслевые особенности как фактор, сдерживающий технологическое развитие». чинах, вызывающих данное явление. При этом большинство из них считает, что важнейшим фактором, провоцирующим уход бизнеса в «тень», являются налоги. Согласно данной точке зрения, рост налоговой нагрузки в стране вызывает адекватный рост масштабов теневой экономики - налогоплательщики уклоняются от уплаты налогов для сокращения возросших издержек ведения бизнеса. М.Г. Арипов (2012. C. 35) утверждает по этому поводу: «...практически все эксперты и аналитики сходятся во мнении, что налоговое бремя является главной причиной ухода экономических агентов в «тень». Схожего мнения придерживаются М.Ю. Малкина и Р.В. Балакина (2013. С. 22) - «...чем выше уровень налогообложения, тем меньше у хозяйствующих субъектов желания платить налог и тем выше теневая составляющая их деятельности». «...Основной причиной ухода в «тень»

** Федотов Дмитрий Юрьевич (fdy@inbox.ru), доктор экономических наук, доцент, Байкальский государственный университет (г. Иркутск, Россия).

ORCID: 0000-0001-9908-802X 


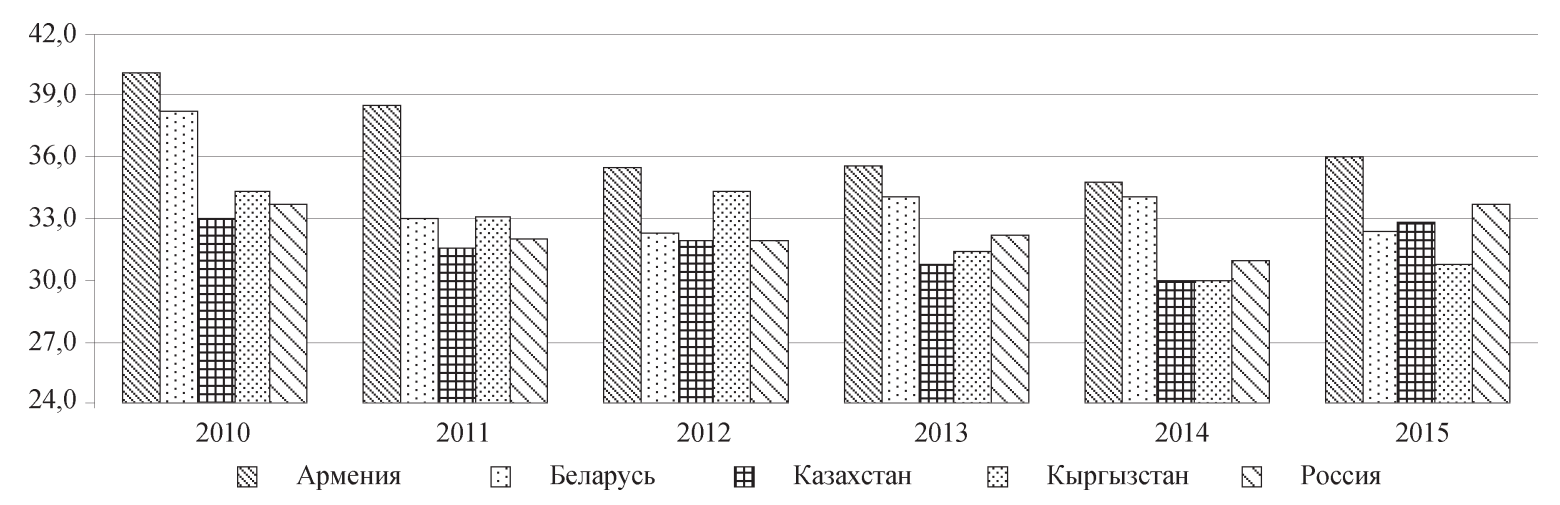

Рис. 1. Величина теневой экономики в странах ЕАЭС, 2010-2015 гг., \% от ВВП

Источник. Авторская разработка по (Medina, Schneider, 2018. PP. 69-74).

были и остаются высокие налоговые ставки» ${ }^{1} ;$ «...экономическим драйвером роста теневой экономики наряду с другими факторами является значительная налоговая нагрузка» (Сухаренко, 2011. С. 153).

Вместе с тем, на наш взгляд, не следует отождествлять два параллельно происходящих процесса - уклонение от уплаты налогов и уход бизнеса в «тень». У представителей бизнеса имеются и другие причины ухода в «тень», связанные с наличием административных барьеров осуществления хозяйственной деятельности, необходимостью получения официальных разрешений со стороны государственных органов и соблюдения иных формальностей. В этой связи гипотезой данного исследования является предположение о том, что налоговая нагрузка не выступает решающим фактором, вызы-

${ }^{1}$ Кокин А.С., Ясенев О.В., Ясенев В.Н. 2014. Теневая экономика в мировом экономическом пространстве. Вестник Нижегородского университета им. Н.И. Лобачевского. № 1. C. $333-337$. вающим рост масштабов теневой экономики. Если высокие налоговые изъятия в государственный бюджет сопровождаются созданием за их счет благоприятных институциональных условий для ведения бизнеса (включая экономическую инфраструктуру), то хозяйствующие субъекты не будут уходить в «тень», пользуясь выгодами легальной деятельности.

Для проверки данной гипотезы был проведен анализ влияния уровня налоговой нагрузки на масштабы теневой экономики в странах ЕАЭС. На рис. 2 показана динамика поступления налоговых доходов в бюджеты стран ЕАЭС в 2010-2018 гг. Согласно представленным данным, на начальном этапе экономической интеграции, в 2010 г., в рассматриваемых странах наблюдался схожий уровень налоговой нагрузки (от 13,0 до 17,1\% ВВП), к 2016 г. разрыв в уровне налоговой нагрузки вырос с 4 до 11 п. п. (с 9,2 до 21,3\%), а к 2018 г. разрыв опять несколько сократился до 9,5 п. п.

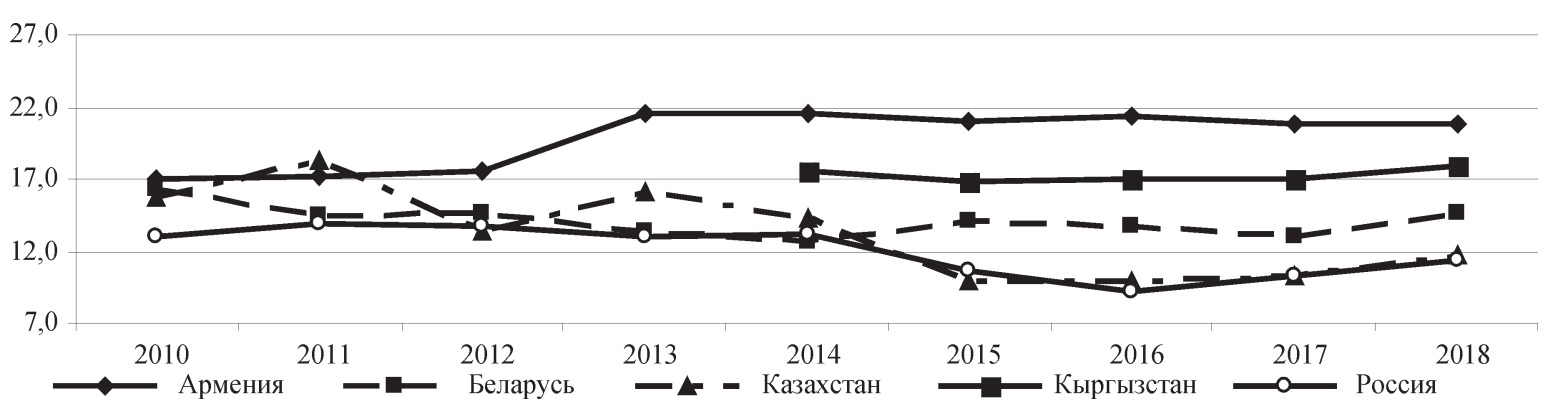

Рис. 2. Поступление налоговых доходов в бюджеты стран ЕАЭС, 2010-2018 гг., \% от ВВП

Примечание. Приведены только налоговые поступления, исключая иные обязательные платежи в бюджетную систему страны, такие как страховые взносы на обязательное социальное страхование и т. п.

Источник. URL: https://data.worldbank.org 
(с 11,4 до 20,9\%). При сохранении данных тенденций следует ожидать гармонизацию основных характеристик налоговых систем стран ЕАЭС.

Задача гармонизации налоговых систем стран ЕАЭС поставлена в Договоре о Евразийском экономическом союзе, принятом 29.05.2014 г., в ст. 71 которого установлено, что «государства-члены определяют направления, а также формы и порядок осуществления гармонизации законодательства в отношении налогов». Налоговая гармонизация предполагает унификацию и систематизацию налогов на территории стран ЕАЭС, координацию налоговой политики и налоговых систем этих стран с целью обеспечения более эффективного распределения ресурсов, движения товаров и факторов производства на интегрированном рынке.

Большое количество авторов отмечает недостаточную степень налоговой гармонизации стран ЕАЭС, сдерживающую экономическую интеграцию стран Союза. Е.И. Комарова (2016. С. 22) считает проведение согласованной налоговой политики необходимым условием экономической интеграции: «..важным аспектом интеграции стран - участниц ЕАЭС является проведение согласованной налоговой политики, стимулирующей развитие национальных экономик, включая совершенствование налогового законодательства и администрирования, преодоление барьеров для трансграничных инвестиций и предпринимательской деятельности». М.С. Жверанцева и Э.Р. Каримова (2014. С. 531) утверждают: «Поскольку в основе налоговой политики ЕАЭС лежит образование единого налогового пространства, приоритетными задачами становятся сближение норм налогового законодательства и механизмов налогового администрирования. Научный подход к решению указанных задач предполагает разработку направлений корректировки и упорядочения нормативно-правовых актов в области налогового законодательства, унификации методов и форм налогового планирования и прогнозирования». Схожую точку зрения о необходимости дальнейшей налоговой гармонизации в рамках ЕАЭС высказывают Ж.А. Абдуллаева (2016), А.А. Боровский (2019) и А.С. Алисенов (2017). Некоторые авторы посвящают свои исследования гармонизации налогообложения отдельных налоговых объектов. Например, К.А. Пономарева (2017) рассматривает направления унификации правил обложения прибыли организаций, Ж.Г. Голодова и Ю.С. Ранчинская (2015) анализируют предпосылки согласования правил обложения доходов физических лиц.

Важнейшим аспектом налоговой гармонизации является консолидация усилий налоговых и правоохранительных органов стран - членов ЕАЭС в противодействии уклонению от уплаты налогов и уходу налогоплательщиков в «тень». А.М. Николаев и Е.Ч. Мурзагалиев (2016) исследуют проблемы разобщенности налогового законодательства и методов совместной борьбы с налоговыми преступлениями в странах ЕАЭС. В.В. Гераськов (2017. С. 102) выявил разночтения в налоговом законодательстве стран ЕАЭС в части привлечения к административной ответственности за налоговые правонарушения: «...можно говорить о сложившейся системе дуализма в регулировании ответственности за правонарушения в сфере налогового законодательства. Данный дуализм приводит к появлению правовых пробелов и неэффективности правоприменения в деятельности уполномоченных органов. На современном этапе развития отношений в ЕАЭС необходимо правовое сотрудничество в борьбе с уклонением от уплаты налогов, что возможно при наличии надежной системы противодействия данному виду правонарушения».

Ряд публикаций раскрывает результаты исследований теневой экономики в странах ЕАЭС и влияния налогов на масштабы «тенезации» бизнеса. F. Schneider (2016) провел анализ уровня теневой экономики стран, входящих в ЕАЭС, и выявил, что рост косвенных налогов, безработицы и коррупции способствует росту теневой экономики. Согласно оценкам А.А. Крылова (2017), на высоком, но довольно схожем, уровне находится теневая экономика в странах ЕАЭС; при этом есть общие причины, вызывающие «тенезацию» бизнеса в них. По мнению В.И. Прасолова и В.А. Волконского (2019. С. 24), постсоветские страны имеют высокий уровень теневой экономики, а одна из причин ее появления - стремление налогоплательщиков 
уклониться от уплаты налогов: «...бщей предпосылкой ... является стремление различных категорий населения добывать средства к своему существованию или обогащению, не выплачивая при этом государству обязательные налоги и платежи». В то же время имеются мнения о наличии рисков, связанных с дальнейшим углублением экономической интеграции в рамках ЕАЭС. А.Н. Шавель (2015) анализирует возможные угрозы развития интеграционных процессов между странами ЕАЭС, которые могут способствовать росту теневой экономики благодаря созданию единого экономического пространства и появлению возможностей для неконтролируемого движения капитала, рабочей силы.

Принимая во внимание результаты исследований, изложенных в рассмотренных выше публикациях, проведем анализ динамики размера теневой экономики в странах ЕАЭС в условиях их экономической интеграции. При этом попытаемся выявить влияние налогов на изменение уровня теневой экономики. На рис. 3 приведены данные о величине теневой экономики в странах ЕАЭС до и после их вступления в экономический союз. На наш взгляд, нельзя однозначно ответить на вопрос, повлияло ли объединение стран в ЕАЭС на изменение масштабов теневой экономики. Однако последствия интеграционных процессов носят скорее позитивный характер. В тех странах, которые давно вступили в Таможенный союз (с 2010 г. Беларусь, Казахстан и Россия), уровень теневой экономики после интеграции снизил-

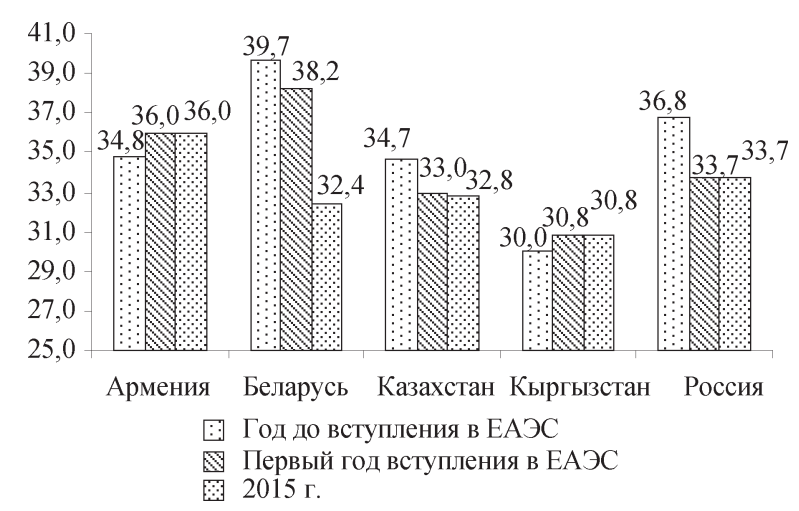

Рис. 3. Величина теневой экономики в странах ЕАЭС до и после вступления в экономический союз, \% от ВВП

Источник. Авторская разработка по (Medina, Schneider, 2018. PP. 69-74). ся. У остальных стран (Армения и Киргизстан вступили в ЕАЭС в 2015 г.) после интеграции наблюдался некоторый рост величины теневой экономики, однако с момента их присоединения к Союзу прошло недостаточно много времени для выявления устойчивых экономических тенденций и закономерностей.

Характеристику взаимосвязи налоговой нагрузки и масштабов теневой экономики в странах ЕАЭС дает коэффициент корреляции между динамикой доли налоговых поступлений в ВВП и динамикой величины теневой экономики (в \% от ВВП), представленный в табл. 1. В большинстве стран ЕАЭС выявлена устойчивая отрицательная зависимость между данными показателями, чаще всего превышающая 0,5. Это означает, что рост налоговой нагрузки в странах ЕАЭС обычно сопровождается снижением масштабов теневой экономики. Данное явление можно объяснить тем, что некоторый рост налоговой нагрузки может сопровождаться увеличением государственных расходов (за счет дополнительных налоговых поступлений) на развитие экономической инфраструктуры и на создание институциональных условий для развития бизнеса, что может стимулировать налого-плательщиков вести хозяйственную деятельность в легальной форме. В то же время снижение налоговой нагрузки, которое сопровождается ухудшением институциональных условий в стране, может провоцировать хозяйствующих субъектов уходить в «тень».

Единственной страной в ЕАЭС, в которой наблюдаются противоположные явления, является Беларусь, где коэффициент корреляции в анализируемом периоде

\section{Коэффициент корреляции между динамикой доли налоговых поступлений в ВВП и динамикой величины теневой экономики в странах ЕАЭС, 2010-2015 гг., \% от ВВП}

\begin{tabular}{|l|c|}
\hline Страна & Коэффициент корреляции \\
\hline Армения & $-0,7299$ \\
\hline Беларусь & 0,5575 \\
\hline Казахстан & $-0,3033$ \\
\hline Кыргызстан & $-1,0000$ \\
\hline Россия & $-0,6401$ \\
\hline
\end{tabular}

Источник. URL: https://data.worldbank.org 
составил 0,5575. В республике наблюдается прямая зависимость между изменением налоговой нагрузки и динамикой масштабов теневой экономики: рост налоговых изъятий в бюджет обычно сопровождается увеличением объема теневой экономики в стране. Для выявления специфики развития налоговых процессов и «тенезации» бизнеса был проведен сравнительный анализ динамики рассматриваемых показателей в странах ЕАЭС, в которых сложилась противоположная корреляционная зависимость между налоговой нагрузкой и уровнем «тенезации» - в Беларуси и в России. На рис. 4 и 5 сопоставлена динамика доли налоговых поступлений в ВВП и масштабов теневой экономики в 2010-2015 гг. от-

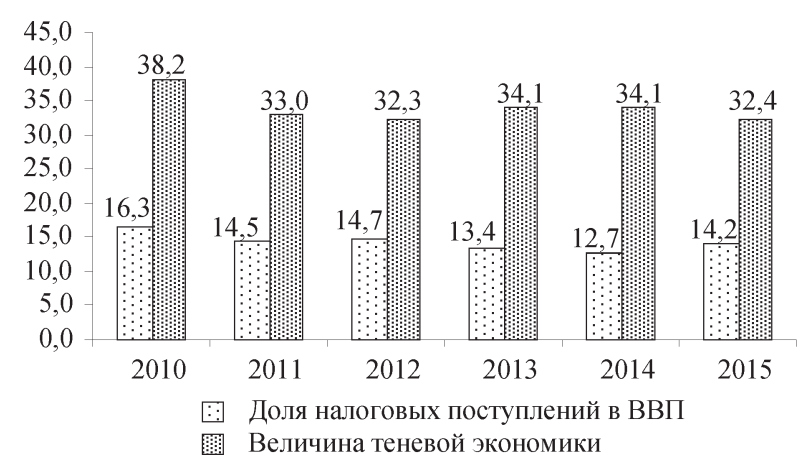

Рис. 4. Динамика доли налоговых поступлений в ВВП и масштабов теневой экономики в Беларуси, 2010-2015 гг., \% от ВВП

Источник. Авторская разработка по: URL: https:/ /data.worldbank.org; (Medina, Schneider, 2018. P. 69).

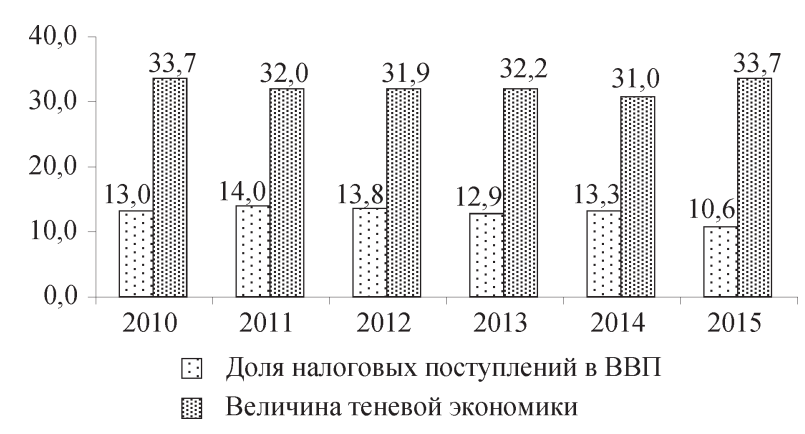

Рис. 5. Динамика доли налоговых поступлений в ВВП и масштабов теневой экономики в России, 2010-2015 гг., \% от ВВП

Источник. Авторская разработка по: URL: https:/ /data.worldbank.org; (Medina, Schneider, 2018. P. 74). дельно в Беларуси и в России. В России рост налоговой нагрузки обычно сопровождается снижением величины теневой экономики, в Беларуси наблюдаются противоположные тенденции.

Неодинаковую реакцию налогоплательщиков на изменение налоговой нагрузки в стране возможно объяснить различием отраслевой структуры налогоплательщиков стран ЕАЭС. Для налогоплательщиков одних отраслей экономики изменение уровня налоговой нагрузки не оказывает существенного влияния на склонность к уходу в «тень», налогоплательщики других отраслей более чувствительны к изменению налоговой нагрузки. На рис. 6 сопоставлена структура поступления налогов по основным видам экономической деятельности в бюджеты Беларуси и России в 2019 г. В Беларуси крупнейшими отраслями, формирующими налоговые доходы государственного бюджета, являются: торговля, обрабатывающие производства, транспорт, строительство. В России большая часть налогов поступает от организаций добывающих отраслей, обрабатывающих производств, торговли, финансовой и страховой деятельности.

Исследователи проблем теневой экономики выявляют несколько видов экономической деятельности с повышенным уровнем «тенезации». Ф. Шнайдер к таким отраслям в странах Европы относит: строительство, торговлю, гостиничный и ресторанный бизнес, обрабатывающую промышленность, транспорт, сельское хозяйство (отрасли перечислены в порядке убывания уровня «тенезации») $)^{2}$. По данным исследования (Fedotov, Nevzorova, 2020), в России наиболее высокий уровень теневой экономики сложился в сфере осуществления операций с недвижимым имуществом, в сельском хозяйстве, гостиничном и ресторанном бизнесе, строительстве. Существенно различается структура налогоплательщиков в Беларуси и России по их склонности уходить в «тень». В Беларуси отрасли экономики с повышенным уровнем «тенезации» в 2019 г. обеспечили поступление $58,2 \%$ всех налоговых доходов в бюджет, в

${ }^{2}$ The Shadow economy in Europe, 2013. URL: https:// www.kearney.com/financial-services/article?/a/the-shadoweconomy-in-europe-2013 


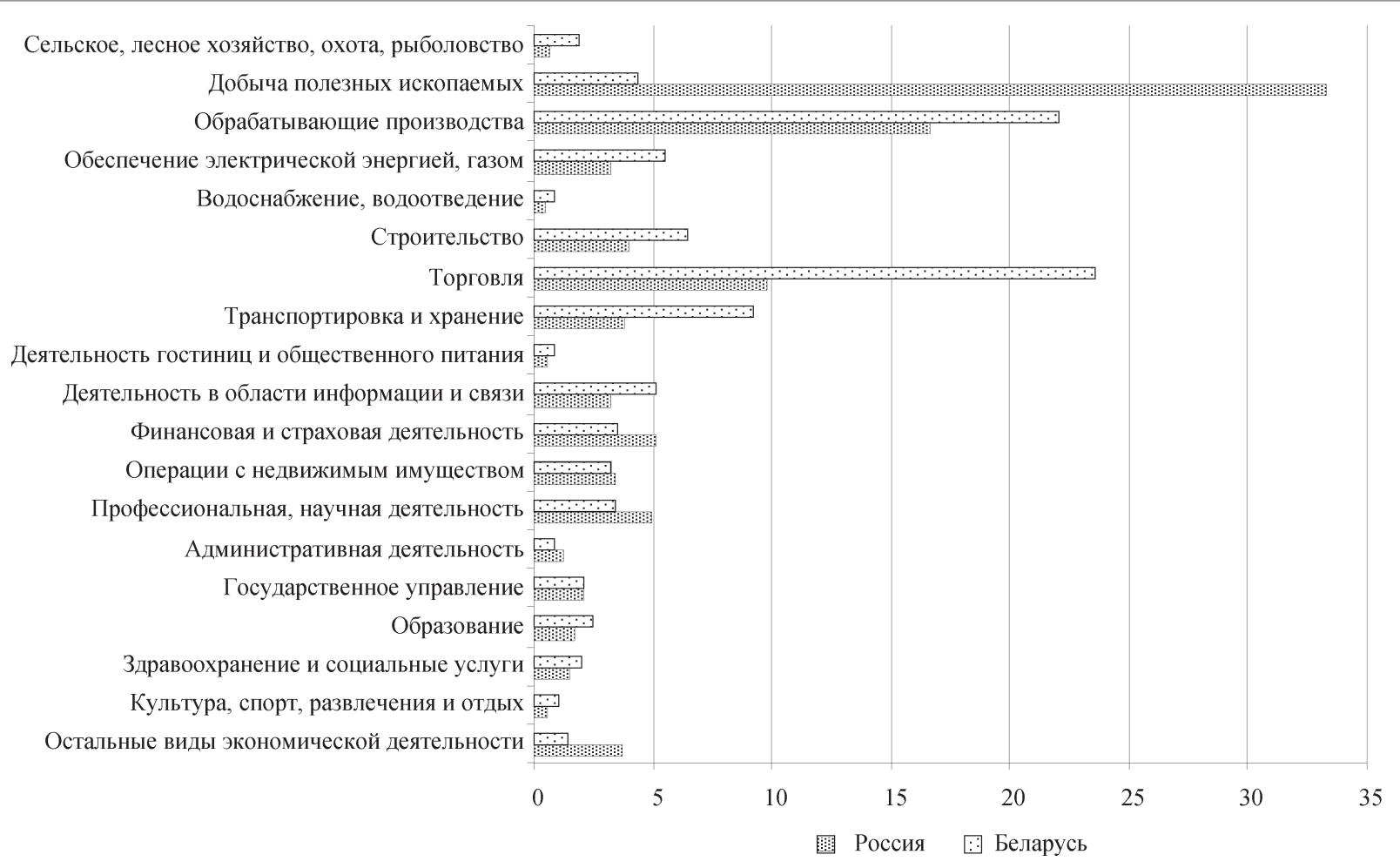

Рис. 6. Структура поступления налогов в бюджеты Беларуси и России по основным видам экономической деятельности, 2019 г.

Источник. URL: http://www.nalog.gov.by; URL: https://www.nalog.ru

России от налогоплательщиков этих отраслей поступило в бюджет только $35,1 \%$ налоговых доходов. Можно предположить, что преобладание в Беларуси среди налогоплательщиков представителей отраслей с повышенным уровнем тенезации создает предпосылки для наиболее сильного проявления негативной реакции налогоплательщиков на повышение налоговой нагрузки в стране. Так как эти налогоплательщики имеют склонности и возможности для ухода в «тень», то на увеличение налогового бремени они реагируют повышением доли теневых хозяйственных операций. В других странах ЕАЭС не наблюдается явный рост «тенезации» экономики под влиянием увеличения налоговой нагрузки.

Таким образом, проведенное исследование позволяет сделать вывод о сохранении неоднородности в налоговых системах стран ЕАЭС несмотря на предпринятые меры по их налоговой гармонизации. Сохраняются ощутимые различия в отрасле- вой структуре налогоплательщиков. Неодинакова реакция налогоплательщиков в их склонности к уходу в «тень» под влиянием изменения уровня налоговой нагрузки. Подтвердилась первоначальная гипотеза о том, что налоговая нагрузка в странах ЕАЭС (за исключением Беларуси) не является решающим фактором, вызывающим рост масштабов теневой экономики. Иные причины могут оказать большее влияние на принятие решения хозяйствующими субъектами о целесообразности ухода в «тень» либо, наоборот, о легализации своего бизнеса (создание благоприятной среды для ведения бизнеса или развитие экономической инфраструктуры за счет дополнительных налоговых доходов).

\section{СПИСОК ЛИТЕРАТУРЫ (REFERENCES)}

Абдуллаева Ж.А. 2016. Кооперация в налоговой политике в рамках Евразийского экономического союза. Инновации и инвестиции. № 12. C. 59-63. [Abdullaeva Zh.A. 2016. Cooperation in tax policy within the framework of the Eurasian 
economic Union. Innovatsii $i$ investitsii. No 12. PP. 59-63. (In Russ.)]

Алисенов А.С. 2017. Перспективы налоговой интеграции государств - членов Евразийского экономического союза. Финансовый журнал. № 5. C. 112-120. [Alisenov A.S. 2017. Tax Integration Prospects of the Eurasian Economic Union Member States. Finansovyy zhurnal. No 5. PP. 112-120. (In Russ.)]

Арипов М.г. 2012. Налоговые механизмы снижения уровня теневой экономики и стимулирования инвестиционной деятельности. Финансы и кредит. № 42. C. 35-41. [Aripov M.G. 2012. Tax mechanisms for reducing the level of the shadow economy and stimulating investment activity. Finansy $i$ kredit. No 42. PP. 35-41. (In Russ.)]

Боровский А.А. 2019. Анализ уровня гармонизации налоговой системы Республики Беларусь со странами - членами ЕАЭС. Вестник Витебского государственного технологического университета. № 2. C. 104-114. [Borowski A. 2019. Analysis of the harmonization level of the tax system of the republic of Belarus with the EAEU countries. Vestnik Vitebskogo gosudarstvennogo tekhnologicheskogo universiteta. No 2. PP. 104-114. (In Russ.)]

Гераськов В.В. 2017. Правовое регулирование административной ответственности за правонарушения в области налогов и сборов в государствах - членах ЕАЭС. Экономика, социология u право. № 3. C. 101-105. [Geraskov V.V. 2017. Legal regulation of administrative responsibility for violations in the field of taxes and fees in the EAEU member States. Ekonomika, sotsiologiya i pravo. No 3. PP. 101-105. (In Russ.)]

Голодова Ж.Г., Ранчинская Ю.С. 2015. Налогообложение доходов физических лиц в странах ЕАЭС: анализ параметров и направления гармонизации. Вестник Российского университета дружбы народов. Серия: Экономика. № 4. С. 79-86. [Golodova Z.G., Ranchinskaya Y.S. 2015. Personal income tax in EAEU: Analysis of parametrs and harmonization. Vestnik Rossiyskogo universiteta druzhby narodov. Seriya: Ekonomika. No 4. PP. 79-86. (In Russ.)]

Жверанцева М.С., Каримова Э.Р. 2014. К вопросу о необходимости и направлениях гармонизации налогообложения прибыли и доходов в Евразийском экономическом союзе. Известия Саратовского университета. Новая серия. Серия: Экономика. Управление. Право. Т. 14. № 3. С. 531536. [Zhverantseva M.S., Karimova E.R. 2014. About the necessity and ways of harmonization of taxation of profits and income in the Eurasian Economic Union. Izvestija Saratovskogo universiteta. Novaja serija. Seriya: Ekonomika. Upravlenie. Pravo. Vol. 14. No 3. PP. 531-536. (In Russ.)]

Комарова Е.И. 2016. Перспективные направления гармонизации налоговых отношений в ус- ловиях евразийской интеграции. Интеллект. Инновации. Инвестищии. № 6. С. 22-26. [Komarova E.I. 2016. Prospective directions of tax harmonization in conditions of Eurasian integration. Intellekt. Innovatsii. Investitsii. No 6. PP. 22-26. (In Russ.)]

Крылов А.А. 2017. Масштабы и структура теневой экономики в странах - членах ЕАЭС. Микроэкономика. № 4. C. 77-83. [Krylov A.A. 2017. Scales and structure of shadow economy in EAEU country-members. Mikroekonomika. No 4. PP. 7783. (In Russ.)]

Малкина М.Ю., Балакин Р.В. 2013. Моделирование взаимосвязи уровня налоговой нагрузки и поступлений от налога на прибыль для регионов Российской Федерации. Финансы и кредum. Т. 19. Вып. 35. С. 21-29. [Malkina M.Yu., Balakin R.V. 2013. Modeling the relationship between the level of tax burden and income tax revenues for the regions of the Russian Federation. Finansy $i$ kredit. Vol. 19. Iss. 3. PP. 21-29. (In Russ.)]

Николаев А.М., Мурзагалиев Е.Ч. 2016. Актуальные проблемы борьбы с налоговыми преступлениями международного характера в новых интеграционных объединениях. Вестник Волгоградского государственного университета. Серия 5: Юриспруденция. Т. 15. № 4. С. 169-176. [Nikolaev A.M., Murzagaliev E.Ch. 2016. Current problems of struggle against international tax crimes in the new integration associations. Vestnik Volgogradskogo gosudarstvennogo universiteta. Seriya 5: Yurisprudentsiya. Vol. 15. No 4. PP. 169-176. (In Russ.)]

Пономарева К.А. 2017. Направления гармонизации налогообложения прибыли и доходов в Евразийском экономическом союзе. Вестник Омского университета. Серия: Право. № 3. С. 4754. [Ponomareva K.A. 2017. Ways of harmonization of income taxes in the Eurasian Economic Union. Vestnik Omskogo universiteta. Seriya: Pravo. No 3. PP. 47-54. (In Russ.)]

Прасолов В.И., Волконский В.А. 2019. Предпринимательство в теневой экономике Азербайджана, Казахстана, России: сравнительное исследование. Управление экономическими системами: электронный научный журнал. № 7. С. 18-37. [Prasolov V.I., Volkonskiy V.A. 2019. Entrepreneurship in the shadow economy of Azerbaijan, Kazakhstan, Russia: A comparative study. Upravlenie ekonomicheskimi sistemami: elektronnyy nauchnyy zhurnal. No 7. PP. 1837. (In Russ.)]

Сухаренко А.Н. 2011. Теневая экономика Дальнего Востока: мрачные перспективы. Ойкумена. Регионоведческие исследования. № 3. С.149-156. [Sukharenko A.N. 2011. Shadow economy of the Far East: dismal prospects. Oykumena. Regionovedcheskie issledovaniya. No 3. PP. 149-156. (In Russ.)]

Шавель А.Н. 2015. Экономико-географические аспекты внешнеторгового взаимодействия Беларуси в рамках Таможенного союза и единого эко- 
номического пространства. Вестник БГУ. Серия 2: Химия. Биология. География. № 1. С. 81-87. [Shavel A.N. 2015. Economy-geographical aspects of foreign trade interaction between Belarus within the Customs Union and common economic space. Vestnik BGU. Seriya 2: Khimiya. Biologiya. Geografiya. No 1. PP. 81-87. (In Russ.)]

Fedotov D.Yu., Nevzorova E.N. 2020. Intersectoral Shadow Economic Linkages and their
Impact on Tax Evasion. Journal of Tax Reform. Vol. 6. No 1. PP. 36-53.

Medina L., Schneider F. 2018. Shadow economies around the world: what did we learn over the last 20 years? IMF Working Papers 18/17. 76 p.

Schneider F. 2016. The size and development of the shadow economies of Ukraine and six other eastern countries over the period of 1999-2015. Экономика развития. № 2. С. 12-20.

In citation: Belorusskiy Ekonomicheskiy zhurnal. 2021. No 2. PP. 55-62.

Belarusian Economic Journal. 2021. No 2. PP. 55-62.

\section{THE LEVEL OF THE SHADOW ECONOMY IN EAEU PARTICIPATING STATES UNDER TAX HARMONIZATION}

\section{Dmitry Fedotov ${ }^{1}$}

Author affiliation: ${ }^{1}$ Baikal State University (Irkutsk, Russia).

Corresponding author. Dmitry Fedotov(fdy@inbox.ru).

ABSTRACT. Comparative analysis of shadow economy level in EAEU participating states is carried out. It gives the assessment on the way taxes affect changes of its scale. A number of standpoints among scholars on the background for shadow economy are considered. Steps taken to achieve tax harmonization are examined. It includes tax unification and systemization in EAEU member countries, coordination of their tax policy and tax system. Statistical methods are used to conduct correlation analysis of shadow economy level and tax burden (shares of the taxes in GDP) interdependence. Sectoral structures of tax payers in Russia and Belarus are compared to reveal aspects of development of tax processes and business 'shadowing'. Results obtained validates an initial assumption that high tax burden is not a key factor for driving economic entities into shadowing to evade taxes.

KEYWORDS: tax, tax burden, shadow economy, sectoral economy, Eurasian Economic Union.

JEL-code: H26, O17.

DOI: $10.46782 / 1818-4510-2021-2-55-62$ 